\title{
EFFECT OF INTRAARTICULAR STEROID INJECTION IN ADDITION TO PHYSICAL MODALITIES IN OSTEOARTHRITIS KNEE
}

\author{
ISLAM MJ ${ }^{1}$, UDDIN MMJ ${ }^{2}$, HOSSAIN MS $^{3}$, AMIN MR $^{4}$, RAHMAN MM $^{5}$, SIDDIQUI MMR ${ }^{6}$, SALEK AKM $^{7}$
}

\begin{abstract}
Context: Osteoarthritis (OA) is the most common form of arthritis accounting for about $30 \%$ of general physician visits. Intrarticular (IA) corticosteroid injections have been used for decades in clinical practice for pain relief and control of local inflammation in OA. In the present study a combined therapy of long acting intra-articular injection in addition to physical modalities of OA knee was given to find out the functional improvement and clinical outcome of the patient.

Methods: It was a prospective interventional non-randomized clinical study conducted in the Department of Physical Medicine \& Rehabilitation, Bangabandhu Sheikh Mujib Medical University (BSMMU), Dhaka, from October, 2011 to March, 2012. Fifty four patients between 35 and 75 years without consideration of gender with a history of not less than three months knee pain with radiographic confirmation of primary osteoarthritis were selected purposefully. Then they were divided randomly in group $A$ and $B$, having 27 patients in each group. Group A received NSAID (non steroidal anti-inflammatory drugs) i.e. aceclofenac $100 \mathrm{mg}$ twice daily for 10 days +omeprazol $20 \mathrm{mg}$ twice daily for 10 days + MWD (micro wave diathermy 20 minutes for 14 days. + therapeutic exercise $+A D L$ (activities of daily living), while Group $B$ received $80 \mathrm{mg}$ intraarticular triamcinolon acetonide injection once followed by NSAID i.e. aceclofenac 100mg twice daily for 10 days + omeprazol $20 \mathrm{mg}$ twice daily for 10 days + MWD 20 minutes for 14 days. + therapeutic exercise + $A D L$. In both groups the patients were observed for six weeks.

Results: The mean of age of patients in group $A$ and B were 52.33 \pm 9.62 years and $52.29 \pm 9.67$ years respectively. In group A, 9 (33.3\%) were male and 18 (66.7\%) were female. In group B, 10 (37.0\%) were male and 18 (63.0\%) were female. Mean visual analogue scale (VAS) during pre treatment in group $A$ and group $B$ were $6.22 \pm 1.60$ and $7.15 \pm 1.56$ respectively. Mean range of motion (ROM) during pre treatment in group $A$ and group $B$ were $117.33 \pm 13.05$ and $112.37 \pm 19.01$ respectively. Mean time taken to walk 50 feet during pre treatment in group $A$ and group $B$ were $18.22 \pm 2.39$ and $18.81 \pm 2.13$ minutes respectively. Mean Western Ontario and Mc Master Universities (WOMAC) index in group A and group B were 60.85 \pm 15.86 and $67.33 \pm 16.33$ minutes respectively. After treatment in both groups visual analogue scale (VAS), range of motion (ROM), time taken to walk 50 feet and Western Ontario and Mc Master Universities (WOMAC) index gradually decreased and range of motion (ROM) gradually increased, which were statistically significant. However, the study conducted with small sample size in a single centre in Dhaka city, which may not be representative for the whole country.
\end{abstract}

Key words: Osteoarthritis, knee joint pain, steroid injection.

J Dhaka Med Coll. 2014; 23(1) : 48-54.

1. Dr. Md. Jahidul Islam, Assistant Professor, Department of Physical Medicine \& Rehabilitation, National Institute of Neurosciences \& Hospital, Dhaka.

2. Dr. M M Jalal Uddin, Assistant Professor, Department of Psychiatry, National Institute of Neurosciences \& Hospital, Dhaka.

3. Dr. Md. Shahadat Hossain, Associate Professor, Department of Physical Medicine \& Rehabilitation, Dhaka Medical College. Dhaka

4. Dr. Md. Ruhul Amin, Assistant Professor, Department of Physical Medicine \& Rehabilitation, Dhaka Medical College. Dhaka.

5. Dr. Md. Moshiur Rahman, Assistant Professor, Department of Physical Medicine \& Rehabilitation, Bangabandhu Sheikh Mujib Medical University (BSMMU), Dhaka.

6. Dr. Md. Mahmudur Rahman Siddiqui, Assistant Professor of Medicine, Anwer Khan Modern Medical College \& Hospital, Dhaka

7. Prof. A.K.M. Salek, Professor, Department of Physical Medicine \& Rehabilitation, Bangabandhu Sheikh Mujib Medical University (BSMMU), Dhaka.

For correspondence: Dr. Md. Jahidul Islam, Assistant Professor, Department of Physical Medicine \& Rehabilitation, National Institute of Neurosciences \& Hospital, Dhaka. Cell Phone: +88-01711070123, Email: jahiddr@yahoo.com 


\section{Introduction:}

Osteoarthritis (OA) is the most common form of arthritis accounting for about $30 \%$ of general physician visits ${ }^{1}$. It may be defined as a heterogeneous group of conditions that lead to joint symptoms and signs which are associated with defective integrity of articular cartilage, in addition to related changes in the underlying bone and at the joint margins ${ }^{2}$. It is usually classified as either primary (idiopathic) or secondary (associated with a known condition). Although OA is present by histologic or radiographic criteria in nearly $80 \%$ of people by the age of 80 years, only half have symtoms ${ }^{3}$, and these are often variable and intermittent. All though variable in its presentation and course of $\mathrm{OA}$ often carries significant morbidity ${ }^{4}$, related to its high prevalence, the reduced ability of those affected to perform both occupational and non-occupational activities ${ }^{5}$.Osteoarthritis is no longer considered a 'degenerative' or 'wear and tear' arthritis, rather involves dynamic biomechanical, biochemical and cellular process ${ }^{6}$. Although articular cartilage is at the center of change, OA is currently viewed as a disease of the entire joint and therefore, the failure of the joint as an organ ${ }^{7}$. Although symptoms are often unilateral, evidence of OA is almost always present bilaterally. However, even when symptoms are bilateral, there is a tendency for one side to be more symptomatic than the other. Unilateral disease may suggest OA secondary to trauma. In contrast to systemic inflammatory arthritis, OA lacks constitutional symptoms. OA is characterized clinically by pain, swelling of joint and limitation of motion. Pathologically \& Radio logically the disease is characterized by focal erosive lesions, cartilage destruction, subchondral sclerosis, cyst formation and large osteophyte at the margin of the joints ${ }^{8}$. Diagnosis of OA knee is based on clinical and substantiated by radiological investigation.

The objectives in managing the patient with OA knee are: reducing/eliminating pain and stiffness, maintain/improve mobility, optimizing function and hence minimizing disability. Therapeutic approaches include pharmacological analgesics e.g. NSAID, intraarticular agents, glucosamine, hyaluronic acid and topical capsaicin, nonpharmacological e.g. patient education, exercise, personal contact, physiotherapy, assistive device, patellar tapping appropriate footwear and surgical intervention may be needed $^{9}$. According to American College of Rheumatology (ACR) for mild symptomatic OA, treatment may include non-pharmacologic methods (patient education, physical \& occupational therapy and other therapies), and pharmacologic therapy including non-opoid oral and tropical (i.e. applied to skin) analgesics. For patient who is unresponsive to this regimen, the use of non steroidal ant inflammatory drugs (NSAIDs) is considered appropriately. A corticosteroid injection is recommended for patients with knee OA, particularly when signs of local inflammation with joint effusion are present. Heat therapy is frequently prescribed to patients with symptomatic knee osteoarthritis (OA). Deep hyperthermia via localized micro wave diathermy (MWD) is effective in several musculoskeletal painful conditions ${ }^{10-16}$. Intrarticular (IA) corticosteroid injections have been used for decades in clinical practice for pain relief and control of local inflammation in $\mathrm{OA}^{17-24}$. Intraarticular corticosteroid injection can be subside local inflammation with pain reduction and it can also reduce progression of structural changes ${ }^{25}$.

Published studies of the effect of a long acting corticosteroid intrarticular injection followed by physical modalities application in OA knee was scanty, moreover, there were less study on the functional impact of these combined therapy based on validated instruments, such as the Western Ontario and McMaster Universities Osteoarthritis Index (WOMAC) in knee OA. As OA knee involves dynamic biomechanical, biochemical and cellular process ${ }^{6}$, its management also include a combination of non-pharmacologic therapy, pharmacologic therapy. Hence, in this study a combined therapy of long acting intra-articular injection in addition to physical modalities of osteoarthritis of knee is given to find out the functional improvement and clinical outcome of the patient. 


\section{Methods:}

This prospective interventional nonrandomized clinical study was conducted in the outpatient department of Physical Medicine \& Rehabilitation, Bangabandhu Sheikh Mujib Medical University (BSMMU), Dhaka, from October, 2011 to March, 2012. Study population were patients having primary mono or bilateral knee osteoarthritis with pain lasting for at least 6 months and having limitation/difficulty of movement of knee joint and osteoarthritis with radiological findings. Patients who were unwillingness to sign informed consent, previous surgery of the affected knee, intraarticular injections with steroids or hyaluronic acid, congenital or acquired inflammatory or neurological diseases involving the knee, taking chronic NSAID or steroid treatment, pregnancy or breastfeeding and contra indications to intraarticular injection were excluded from the study. The 54 patients were divided randomly in group A $\&$ B. Group A received NSAID (non steroidal anti-inflammatory drugs) i.e. aceclofenac $100 \mathrm{mg}$ twice daily for 10 days + omeprazol 20mg twice daily for 10 days + MWD (micro wave diathermy 20 minutes for 14 days. + therapeutic exercise + ADL (activities of daily living), while Group B received $80 \mathrm{mg}$ intraarticular triamcinolon acetonide injection once followed by NSAID i.e. aceclofenac $100 \mathrm{mg}$ twice daily for 10 days + omeprazol 20mg twice daily for 10 days + MWD 20 minutes for 14 days. + therapeutic exercise + ADL. In both groups the patients were observed for six weeks. Study parameters used to assess the disease activity \& functional capability of the patients were: 1) Visual analogue scale (VAS), 2) Range of motion (ROM) and 3) Western Ontario and McMaster Universities (WOMAC) index. After taking the formal consent of the patient, details history was taken and a preset data form was filled up for every patient. Past history of illness $\&$ any systemic disease was inquired cautiously. Clinical examination was done systematically. Base line investigations were done e.g. CBC, ESR \& $\mathrm{Hb} \%$, RBS, Serum creatinine, urine for $\mathrm{R} / \mathrm{M} / \mathrm{E}$, serum uric acid \& SGPT. X-ray of the affected knee joints were also done. All reports were properly recorded in the data sheet. Treatment was delivered in each group as per scheduled. Every patient was followed up in each week with up to six weeks. Data were analyzed by SPSS version 16.0.

\section{Results:}

The mean of age of patients in group A and B were $52.33 \pm 9.62$ years and $52.29 \pm 9.67$ years respectively (table-I). In group A, 9 (33.3\%) were male and $18(66.7 \%)$ were female. In group B, $10(37.0 \%)$ were male and 18 (63.0\%) were female (table-II). In Group A, highest number of patients had knee pain in both joins $(48.1 \%)$ followed by right knee pain in 11 (40.7\%) patients. Only $3(11.1 \%)$ patients had pain in the left knee joint. In group $B$, more than half of the patients had knee pain in both joins $(51.9 \%)$ followed by right knee pain in 9 (33.3\%) patients. Only $4(14.8 \%)$ patients had pain in the left knee joint (table-III). Mean visual analogue scale (VAS) during pre treatment in group A and group B were $6.22 \pm 1.60$ and $7.15 \pm 1.56$ respectively. Mean range of motion (ROM) during pre treatment in group $A$ and group B were $117.33 \pm 13.05$ and $112.37 \pm 19.01$ respectively. Mean time taken to walk 50 feet during pre treatment in group A and group B were $18.22 \pm 2.39$ and $18.81 \pm 2.13$ minutes respectively. Mean Western Ontario and Mc Master Universities (WOMAC) index in group $A$ and group B were $60.85 \pm 15.86$ and $67.33 \pm 16.33$ minutes respectively. After treatment in both groups visual analogue scale (VAS), range of motion (ROM), time taken to walk 50 feet and Western Ontario and Mc Master Universities (WOMAC) index gradually decreased and range of motion (ROM) gradually increased, which were statistically significant.

\section{Table I}

Distribution of patient by age group

\begin{tabular}{lccl}
\hline Age group & \multicolumn{2}{c}{ Group } & p value \\
& Group-A & Group-B & \\
\hline$<40$ & $02(07.4)$ & $03(11.1)$ & \\
$40-49$ & $12(44.4)$ & $09(33.3)$ & \\
$50-59$ & $07(25.9)$ & $09(33.3)$ & \\
60 and above & $06(22.3)$ & $06(22.3)$ & \\
Total & $27(100.0)$ & $27(100.0)$ & \\
Mean \pm SD & $52.33 \pm 9.62$ & $52.29 \pm 9.67$ & 0.989 \\
\hline
\end{tabular}

Student's ' $t$ ' test was done to measure the level of significance. Figures within parentheses indicate percentage. 
Table II

Distribution of patients by sex

\begin{tabular}{lccl}
\hline Sex & \multicolumn{2}{c}{ Group } & p value \\
& Group-A & Group-B & \\
\hline Male & $09(33.3)$ & $10(37.0)$ & \\
Female & $18(66.7)$ & $17(63.0)$ & \\
Total & $27(100.0)$ & $27(100.0)$ & 0.776 \\
\hline
\end{tabular}

Chi-square test was done to measure the level of significance. Figures within parentheses indicate percentage.

Table III

Distribution of patient by knee pain $(n=54)$

\begin{tabular}{lccc}
\hline Knee pain & \multicolumn{2}{c}{ Group } & p value \\
& Group-A & Group-B & \\
\hline Right & $11(40.7)$ & $09(33.3)$ & \\
Left & $03(11.1)$ & $04(14.8)$ & \\
Both & $13(48.1)$ & $14(51.9)$ & \\
\hline Total & $27(100.0)$ & $27(100.0)$ & 0.827 \\
\hline
\end{tabular}

Chi-square test was done to measure the level of significance. Figures within parentheses indicate percentage.

\section{Table IV}

Distribution of patient according to characteristics of pain $(n=54)$

\begin{tabular}{lccc}
\hline Analysis of pain & \multicolumn{2}{c}{ Group } & $\mathrm{p}$ \\
& Group-A & Group-B & value \\
\hline Onset & & & \\
$\quad$ Gradual & $26(96.3)$ & $22(81.5)$ & 0.083 \\
$\quad$ After trauma & $01(03.7)$ & $05(18.5)$ & \\
Site of pain & & & \\
$\quad$ Localized in knee & $24(88.9)$ & $23(85.2)$ & 0.685 \\
$\quad$ Knee \& Other Joints & $03(11.1)$ & $04(14.8)$ & \\
Time of occurrence & & & \\
$\quad \begin{array}{llll}\text { Morning } \\
\text { Evening }\end{array}$ & $13(48.1)$ & $16(59.3)$ & 0.413 \\
Duration of pain & $14(51.9)$ & $11(40.7)$ & \\
$\quad$ Constant & $20(74.1)$ & $22(81.5)$ & 0.513 \\
$\quad$ Intermittent & $07(25.9)$ & $5(18.5)$ & \\
Radiation of pain & & & \\
$\quad$ Yes & $01(03.8)$ & $03(10.7)$ & \\
if yes, type & $01(03.8)$ & $03(10.7)$ & \\
$\quad$ Both & & & \\
Severity of pain & $04(14.8)$ & $01(03.7)$ & 0.348 \\
$\quad \begin{array}{l}\text { Mild } \\
\text { Moderate }\end{array}$ & $13(48.1)$ & $16(59.3)$ & \\
Severe & $10(37.0)$ & $10(37.0)$ & \\
\hline
\end{tabular}

Chi-square test was done to measure the level of significance. Figures within parentheses indicate percentage.
Table V

Distribution of patient according to examination of the knee $(n=54)$.

\begin{tabular}{|c|c|c|c|c|}
\hline \multirow{2}{*}{$\begin{array}{l}\text { Examination } \\
\text { the knee }\end{array}$} & \multirow{2}{*}{ of } & \multicolumn{2}{|c|}{ Group } & \multirow{3}{*}{$\begin{array}{c}\mathrm{p} \\
\text { value } \\
0.639\end{array}$} \\
\hline & & Group-A & Group-B & \\
\hline \multirow[t]{2}{*}{ Contour } & Normal & 03(11.1) & $02(07.4)$ & \\
\hline & Swelling & 24(88.9) & 25 (92.6) & \\
\hline Local & Absent & 03(11.1) & $04(14.8)$ & 0.685 \\
\hline Swelling & Present & 24(88.9) & $23(85.2)$ & \\
\hline Local & Normal & $12(44.4)$ & 08 (29.6) & 0.260 \\
\hline Temperature & Raised & $15(55.6)$ & $19(70.4)$ & \\
\hline Eliciting & Absent & $02(07.4)$ & 01 (03.7) & 0.552 \\
\hline fluctuation & Present & 25(92.6) & 26 (96.3) & \\
\hline Leg length & Yes & $02(07.4)$ & $01(03.7)$ & 0.552 \\
\hline discrepancy & No & 25(92.6) & 26 (96.3) & \\
\hline \multirow[t]{2}{*}{ Deformity } & Genu varus & $07(25.9)$ & $10(37.0)$ & 0.379 \\
\hline & No deformity & y20(74.1) & 17 (63.0) & \\
\hline
\end{tabular}

Chi-square test was done to measure the level of significance. Figures within parentheses indicate percentage.

\section{Table VI}

Distribution of patient according to test of patella $(n=54)$

\begin{tabular}{lllll}
\hline Test of patella & \multicolumn{2}{c}{ Group } & p \\
& & Group-A & Group-B & value \\
\hline Position & Normal & $20(74.1)$ & $14(51.9)$ & 0.091 \\
& Shifted-high $07(25.9)$ & $13(48.1)$ & \\
Shape & Normal & $21(77.8)$ & $16(59.3)$ & 0.143 \\
& Broadening & $06(22.2)$ & $11(40.7)$ & \\
Mobility & Normal & $08(29.6)$ & $09(33.3)$ & 0.770 \\
& Painful & $19(70.4)$ & $18(66.7)$ & \\
Tenderness & Present & $22(81.5)$ & $25(92.6)$ & 0.224 \\
& Absent & $05(18.5)$ & $02(07.4)$ & \\
& & $23(85.2)$ & $24(88.9)$ & 0.685 \\
Patellar tap & Present & $04(14.8)$ & $03(11.1)$ & \\
& Absent & 04 &
\end{tabular}

Chi-square test was done to measure the level of significance. Figures within parentheses indicate percentage. 
Table VII

Distribution of patient according to $\operatorname{VAS}(n=54)$

\begin{tabular}{lccc}
\hline Treatment period & \multicolumn{2}{c}{ Group } & p value \\
& Group-A & Group-B & \\
\hline Pre treatment & $6.22 \pm 1.60$ & $7.15 \pm 1.56$ & 0.036 \\
After 1 week & $5.22 \pm 1.58$ & $5.30 \pm 1.54$ & 0.862 \\
After 2 week & $4.85 \pm 1.70$ & $3.92 \pm 1.46$ & 0.037 \\
After 3 week & $4.25 \pm 1.70$ & $3.29 \pm 1.51$ & 0.032 \\
After 4 week & $4.07 \pm 1.66$ & $2.48 \pm 1.45$ & 0.001 \\
After 5 week & $3.48 \pm 1.78$ & $1.92 \pm 1.17$ & 0.001 \\
After 6 week & $3.04 \pm 1.72$ & $1.33 \pm 1.10$ & 0.001 \\
\hline
\end{tabular}

Student's ' $t$ ' test was done to measure the level of significance.

Table VIII

Distribution of patient according to ROM $(n=54)$

\begin{tabular}{lcccc}
\hline Treatment period & \multicolumn{2}{c}{ Group } & p value \\
& Group-A & Group-B & \\
\hline Pre treatment & $117.33 \pm 13.05$ & $112.37 \pm 19.01$ & 0.269 \\
After 1 week & $119.67 \pm 12.03$ & $118.18 \pm 12.92$ & 0.665 \\
After 2 week & $121.66 \pm 11.29$ & $122.03 \pm 10.80$ & 0.902 \\
After 3 week & $122.92 \pm 10.51$ & $125.44 \pm 8.96$ & 0.348 \\
After 4 week & $124.81 \pm 9.62$ & $128.29 \pm 6.84$ & 0.132 \\
After 5 week & $125.96 \pm 9.25$ & $129.96 \pm 5.48$ & 0.059 \\
After 6 week & $127.29 \pm 8.60$ & $131.67 \pm 4.35$ & 0.022 \\
\hline
\end{tabular}

Student's ' $t$ ' test was done to measure the level of significance.

Table IX

Distribution of patient according to time taken to walk 50 feet $(n=54)$

$\overline{\text { Treatment period } \quad \text { Group } \quad \mathrm{p} \text { value }}$
Group-A Group-B

\begin{tabular}{llll}
\hline Pre treatment & $18.22 \pm 2.39$ & $18.81 \pm 2.13$ & 0.341
\end{tabular}

After 1 week $\quad 17.18 \pm 2.30 \quad 17.14 \pm 2.10 \quad 0.951$

After 2 week $\quad 16.81 \pm 2.18 \quad 15.96 \pm 1.81 \quad 0.125$

After 3 week $\quad 16.40 \pm 2.42 \quad 15.33 \pm 1.90 \quad 0.076$

$\begin{array}{llll}\text { After } 4 \text { week } \quad 15.96 \pm 2.28 & 14.78 \pm 2.02 & 0.049\end{array}$

After 5 week $\quad 15.40 \pm 2.6014 .44 \pm 1.86 \quad 0.125$

After 6 week $\quad 15.07 \pm 2.49 \quad 13.62 \pm 2.04 \quad 0.024$

Student's ' $\mathrm{t}$ ' test was done to measure the level of significance.
Table X

Distribution of patient according to WOMAC index $(n=54)$

\begin{tabular}{lccc}
\hline \multirow{2}{*}{ Treatment period } & \multicolumn{2}{c}{ Group } & p value \\
& Group-A & Group-B & \\
\hline Pre treatment & $60.85 \pm 15.8667 .33 \pm 16.33$ & 0.145 \\
After 1 week & $53.96 \pm 15.5455 .63 \pm 14.91$ & 0.689 \\
After 2 week & $47.74 \pm 15.9747 .03 \pm 15.21$ & 0.869 \\
After 3 week & $41.18 \pm 15.7438 .96 \pm 14.49$ & 0.592 \\
After 4 week & $35.89 \pm 15.4630 .96 \pm 13.74$ & 0.222 \\
After 5 week & $30.89 \pm 16.1122 .48 \pm 11.58$ & 0.032 \\
After 6 week & $25.29 \pm 15.3013 .85 \pm 9.62$ & 0.002 \\
\hline
\end{tabular}

Student's ' $t$ ' test was done to measure the level of significance.

\section{Discussion:}

This study was aimed to explore the effects of combined therapy of long acting intraarticular injection in addition to physical modalities of OA knee and to find out the functional improvement and clinical outcome of the patient. 54 patients were included in the study. Intrarticular (IA) corticosteroid injections have been used for decades in clinical practice for pain relief and control of local inflammation in OA. Intrarticular corticosteroid injections are part of the treatment paradigm suggested in the American College of Rheumatology (ACR) practice for the treatment of knee $\mathrm{OA}^{24}$. Intra articular corticosteroid injection can be subside local inflammation with pain reduction and it can also reduce progression of structural changes $^{25}$. Godwin $\&$ Dawes $^{26}$ in a systematic review with meta-analysis showed that intraarticular corticosteroid injection results in clinically and statistically significant reduction in osteoarthritic knee pain 1 week after injection. Treatment effects were consistent with previous studies by Ravaud et al. ${ }^{27}$; Friedman $\&$ Moore ${ }^{28}$; Dieppe et al. ${ }^{29}$ and Jones \& Doherty ${ }^{30}$. Gaffney et al. ${ }^{31}$ showed that single intraarticular injection of triamcinolone acetonide to patients with knee osteoarthritis provided short term pain relief and increased benefit was associated with both clinical evidence of joint effusion and successful aspiration of synovial fluid at the time of injection. 
Uthman et al. ${ }^{32}$ have studied 70 patients fulfilling the American College of Rheumatology criteria for primary knee osteoarthritis who were randomly chosen to receive intraarticular injections of a corticosteroid $(40 \mathrm{mg}$ triamcinolone acetonide) or a vehicle, at three month intervals, for a prospective period of two years. At the one and two year follow up evaluations, the patients injected with triamcinolone acetonide showed a trend toward greater symptom improvement, especially at the first year follow up, for the WOMAC pain subscale, night pain assessment, and the range of movement $(p=0.05)$ compared with patients injected with saline. Moreover, in a study by Raynauld et al. ${ }^{33}$ showed that knee pain and stiffness were significantly improved throughout the two year study, by repeated injections of triamcinolone acetonide compared with saline injections.

However, one limitation of the present study was that it was conducted in a single centre in Dhaka city, which may not be representative for the whole country. Small sample size was also a limitation of this study. Due to time constraint patients were observed for six weeks only.

\section{Conclusion:}

Despite the lack of strong, convincing, and reproducible evidence that intraarticular therapy significantly alters the short term outcome and even less so the progression of osteoarthritis, corticosteroid injection is one of the mainstays of the management of osteoarthritis, in particular, osteoarthritis of the knee. In the present study there was statistically significant difference found in VAS, ROM, time taken to walk 50 feet and WOMAC index between the groups.

\section{References:}

1. Kramer JS, Yelin EH, Epstein WV. Social and economic impacts of four musculoskeletal conditions: a study using national community based data. J Rheumatol 1983; 26: 901-7.

2. Altman RD, Asch E, Bloch D, Bole G, Borenstein $\mathrm{D}$, Brandt K, et al. Development of criteria for the classification and reporting of osteoarthritis: Classification of osteoarthritis of the knee. Arthritis Rheum 1986; 29(8): 1039-49.
3. Hochberg MC, Lawrence RC, Everett DF, CornoniHuntley J. Epidemiologic associations of pain in osteoarthritis of the knee: data from the National Health and Nutrition Examination Survey and the National Health and Nutrition Examination. 1: epidemiologic follow-up survey. Semin Arthritis Rheum 1989; 18(suppl 2): 4-9.

4. Lawrence RC, Hochberg MC, Kelsey JL, McDuffie FC, Medsger TA Jr, Felts WR, et al. Estimates of the prevalence of selected arthritic and musculoskeletal diseases in the United States. J Rheumatol 1989; 16(4): 427-41.

5. Levy E, Ferme A, Perocheau D, Bono I. Socioeconomic costs of osteoarthritis in France. Rev Rhum 1993; 60: 635-75.

6. Kuettner KE, Goldberg VM. Introduction. In: Kuettner KE, Goldberg VM, eds. Osteoarthritis disorders. Rosemont: American Academy of Orthopaedic Surgeons; 1995.

7. Lozada CJ, Altman RD. Chondroprotection in osteoarthritis. Bull Rheum Dis 1997; 46: 5-7.

8. Mankin J, Clinical features of osteoarthritis. In: Kelly WN, Harris ED Jr, Ruddy S, Sledge CB, eds. Textbook of rheumatology. $7^{\text {th }}$ ed. Vol. 2 . Philadelphia: WB Saunders; 2005.

9. Choudhury MR, Zaman MM, Huq SM, Alam F, Hakim F, Saha PR, et al. A review on osteoarthritis. J Bangladesh Coll Phys Surg 2005; 23(3): 123-36.

10. Giombini A, Giovannini V, Di Cesare A, Pacetti $\mathrm{P}$, Ichinoseki-Sekine $\mathrm{N}$, Shiraishi $\mathrm{M}$, et al. Hyperthermia induced by microwave diathermy in the management of muscle and tendon injuries. Br Med Bull 2007; 83: 379-96.

11. Di Cesare A, Giombini A, Dragoni S, Agnello L, Ripani M, Saraceni VM, et al. Calcific tendinopathy of the rotator cuff. Conservative management with $434 \mathrm{Mhz}$ local microwave diathermy (hyperthermia): a case study. Disabil Rehabil 2008; 30(20-22): 1578-83.

12. Giombini A, Di Cesare A, Safran MR, Ciatti R, Maffulli N. Short-term effectiveness of hyperthermia for supraspinatus tendinopathy in athletes: a short-term randomized controlled study. Am J Sports Med 2006; 34(8): 1247-53.

13. Kaplan LD, Chu CR, Bradley JP, Fu FH, Studer RK. Recovery of chondrocyte metabolic activity after thermal exposure. Am J Sports Med 2003; 31(3): 392-8.

14. Weinberger A, Fadilah R, Lev A, Levi A, Pinkhas $\mathrm{J}$. Deep heat in the treatment of inflammatory joint disease. Med Hypotheses 1988; 25(4): 231-3. 
15. Cetin N, Aytar A, Atalay A, Akman MN. Comparing hot pack, short-wave diathermy, ultrasound, and TENS on isokinetic strength, pain, and functional status of women with osteoarthritic knees: a single-blind, randomized, controlled trial. Am J Phys Med Rehabil 2008; 87(6): 443-51.

16. Robertson VJ, Ward AR, Jung P. The effect of heat on tissue extensibility: a comparison of deep and superficial heating. Arch Phys Med Rehabil 2005; 86(4): 819-25.

17. Balch HW, Gibson JM, El-Ghobarey AF, Bain LS, Lynch MP. Repeated corticosteroid injections into knee joints. Rheumatol Rehabil 1977; 16: 137-40.

18. Blyth T, Hunter JA, Stirling A. Pain relief in the rheumatoid knee after steroid injection: a singleblind comparison of hydrocortisone succinate, and triamcinolone acetonide or hexacetonide. $\mathrm{Br} \mathrm{J}$ Rheumatol 1994; 33: 461-3.

19. Cederlof S, Jonson G. Intraarticular prednisolone injection for osteoarthritis of the knee: a double blind test with placebo. Acta Chir Scand 1966; 132: $532-7$.

20. Dieppe PA, Sathapatayavongs B, Jones HE, Bacon PA, Ring EF. Intra-articular steroids in osteoarthritis. Rheumatol Rehabil 1980; 19: 212-7.

21. Friedman DM, Moore ME. The efficacy of intraarticular steroids in osteoarthritis: a doubleblind study. J Rheumatol 1980; 7: 850-6.

22. Gray RG, Gottlieb NL. Intra-articular corticosteroids: an updated assessment. Clin Orthop 1983; 177: 235-63.

23. Valtonen EJ. Clinical comparison of triamcinolone hexacetonide and betamethasone in the treatment of osteoarthrosis of the knee-joint. Scand J Rheumatol Suppl 1981; 41: 1-7.

24. American College of Rheumatology Subcommittee on Osteoarthritis Guidelines. Recommendations for the medical management of osteoarthritis of the hip and knee: 2000 update. Arthritis Rheum 2000; 43(9): 1905-15.
25. Pelletier JP, Martel-Pelletier J, Cloutier JM, Woessner JF Jr. Proteoglycan-degrading acid metalloprotease activity in human osteoarthritic cartilage, and the effect of intraarticular steroid injections. Arthritis Rheum 1987; 30(5): 541-8.

26. Godwin M, Dawes M. Intra-articular steroid injections for painful knees Systematic review with meta-analysis. Can Fam Physician 2004; 50: 241-8.

27. Ravaud P, Moulinier L, Giraudeau B, Ayral X, Guerin C, Noel E, et al. Effects of joint lavage and steroid injection in patients with osteoarthritis of the knee: results of a multicenter, randomized, controlled trial. Arthritis Rheum 1999; 42(3): 47582 .

28. Friedman DM, Moore ME. The efficacy of intraarticular steroids in osteoarthritis: a doubleblind study. J Rheumatol 1980; 7(6): 850-6.

29. Dieppe P, Cushnaghan J, Jasani MK, McCrae F, Watt I. A two-year, placebo-controlled trial of nonsteroidal anti-inflammatory therapy in osteoarthritis of the knee joint. $\mathrm{Br} \mathrm{J}$ Rheumatol 1993; 32(7): 595-600

30. Jones A, Doherty M. Intra-articular corticosteroids are effective in osteoarthritis but there are no clinical predictors of response. Ann Rheum Dis 1996; 55(11): 829-32.

31. Gaffney K, Ledingham J, Perry JD. Intra-articular triamcinolone hexacetonide in knee osteoarthritis: factors influencing the clinical response. Ann Rheum Dis 1995; 54(5): 379-81.

32. Uthman I, Raynauld JP, Haraoui B. Intraarticular therapy in osteoarthritis. Postgrad Med J 2003; 79: 449-53.

33. Raynauld JP, Buckland-Wright C, Ward R, Choquette D, Haraoui B, Martel-Pelletier J, et al. Safety and efficacy of long-term intraarticular steroid injections in osteoarthritis of the knee: a randomized, double-blind, placebo-controlled trial. Arthritis Rheum 2003; 48(11): 3300. 